\title{
REFLETINDO A TRAJETÓRIA HISTÓRICA DA ASSISTÊNCIA PSIQUIÁTRICA
}

\author{
REFLECTING ON THE HISTORY OF PSYCHIATRIC CARE \\ AL REFLEXIONAR LA TRAYECTORIA HISTÓRICA DE LAASISTENCIA \\ PSIQUIÁTRICA
}

\author{
Elizabeth Esperidião \\ Maria Alice Ornellas Pereira ${ }^{2}$
}

\begin{abstract}
RESUMO: Buscamos, através de uma revisão bibliográfica critica, a compreensão das diferentes concepçōes teóricas e tendências de atuação que culminaram com a Reforma Psiquiátrica Brasileira. A nossa critica se traduz em questionamentos dos rumos da assistência, uma vez que atualmente encontramo-nos num periodo de transformaçōes ideológicas, estruturais e politicas nas açōes de Saúde Mental, que fundamentam uma possivel mudança do modelo vigente.
\end{abstract}

PALAVRAS-CHAVE: assistëncia psiquiátrica, psiquiatria, saúde mental

\section{INTRODUÇĀO}

Este trabalho discute, no plano histórico, as formas de assistência psiquiátrica, tendo como objetivo refletir sobre a trajetória da assistência psiquiátrica, diante das tendências que culminaram na Reforma Psiquiátrica Brasileira. Ao longo da história da psiquiatria, verificamos as seguintes tendências:

- de passagem de uma explicação baseada em forças sobrenaturais, para a observação e classificação empiricas;

- da mera observação e classificação dos distúrbios mentais, para uma tentativa de explicação em termos orgânicos;

- das explicações puramente orgânicas para as explicações no plano psicológico individual; e finalmente,

- das explicaçōes psicológicas individualistas para uma abordagem mais ampla, que considera o contexto sócio-cultural, especialmente o contexto familiar, em que o paciente se encontra.

Com base nessa revisão histórica, acreditamos na importância de se construir um novo projeto terapêutico, inclusive no contexto da assistência psiquiátrica brasileira, a ser discutido e articulado com os setores envolvidos no modelo de saúde a ser implementado.

\section{TENDÊNCIAS ATRAVÉS DA HISTÓRIA}

As raizes das concepções de assistência psiquiátrica atualmente existentes podem ser identificadas a partir de periodos históricos remotos. Entre os povos primitivos, havia suposiçőes referentes ao conceito de doença, que eram sempre atribuidas a forças externas que atuavam

\footnotetext{
'Psicóloga e Enfermeira Psiquiátrica. Professora da Faculdade de Enfermagem/UFG. Mestranda EERPNSP

${ }^{2}$ Enfermeira Psiquiátrica. Professora Doutora do Departamento de Enfermagem Psiquiátrica e Ciências Humanas EERPIUSP.
} 
no corpo humano. Tais forças eram concebidas na forma da mitologia (deuses, demônios, bruxas e influências do além). Posteriormente surgiram novos modelos de pensamento e de açăo, localizando as causas da perturbação mental no contexto dos próprios sujeitos e, a partir dai, preconizando cuidados mais humanitários aos mentalmente perturbados, com recomendações de atividades físicas e recreativas, como complemento aos exorcismos a que eram submetidos. Houve, com o passar da história, uma revivescência das explicaçōes espirituais e sobrenaturais, alternando-se com o interesse e preocupaçăo maior quanto ao estudo empirico (observação e classificação) dos transtornos mentais.

Assim, a doença mental, suas causas e tratamentos têm representações diferentes, desde os povos primitivos até as comunidades cientificas de hoje, embora algumas idéias recorrentes possam ser observadas entre a população, mesmo em sociedades mais avançadas tecnologicamente.

A Psiquiatria é a mais jovem das grandes especialidades médicas; ela lida com a mente, com as emoções e comportamento, aspectos do ser humano ainda pouco compreendidos. Como outros ramos da medicina, ela se beneficiou da imaginação, da especulação, do zelo missionário, do proselitismo e especialmente da investigaçāo cientifica. (Solomon, 1975). Entretanto, ainda não tem a mesma tradição clínica da medicina em geral. Não é possivel prever como as transformações geradas pelo progresso cientifico e tecnológico mobilizarão esta especialidade e seus profissionais, os estudiosos e a população, pois observa-se que muitas idéias e concepçōes acerca da doença mental, do seu portador e das possibilidades terapêuticas, mantêm-se cristalizadas no tempo.

Por outro lado, ocorrem transformações no modo de perceber o outro, havendo mudanças de um modelo de conhecimento naturalista, ampliando para uma visão fenomenológica e cultural. Dessa forma, é inegável o desenvolvimento da área, com consequeências importantes quanto ao lugar ocupado pela Psiquiatria no ensino e pela atitude assumida em relação a ela, bem como o empenho científico no sentido de se tentar desestigmatizá-la, enquanto ciência do conhecimento.

A Psiquiatria traz ao longo da sua história alguns marcos que nortearam o atendimento ao doente mental; até os fins do século XVIII, jamais foi tratada como especialidade autônoma. Coube a Philippe Pinel (1745-1826) realizar na França a primeira grande revolução no tratamento dos mentalmente enfermos: obteve, não sem dificuldades e ameaças, o direito de libertar os doentes, de dar-lhes espaço, de reabilitá-los na condição de seres humanos, imprimindo já nesta época, um interesse pelo cuidado humanitário dessas pessoas, através da introdução de formas terapêuticas, utilizando o trabalho, principios de ordem nos hospicios e sociabilidade como fim e como instrumento de cura.

Enquanto disciplina didática e clinica, a Psiquiatria nasceu no inicio do século XIX, sobretudo na França e na Alemanha, passando por algumas fases que se salientam: a fase descritiva (registro, descrição e classificação dos sintomas), a fase psicológica (descobrimento e análise dos mecanismos psicológicos e funcionais dos sintomas), a fase psicodinâmica, nascida na obra de Freud (descobrimento das motivaçōes profundas ligadas a acontecimentos antigos), a fase que recebe a influência filosófica, a partir dos estudos de Jaspers e Biswanger (interpretação dos distúrbios mentais à luz da fenomenologia e da filosofia existencial, que objetivam a compreensão do doente e não apenas de seus sintomas). Rotelli (1979) diz que este último período significou o primeiro instrumento de desmacaramento do terreno ideológico - sobre o qual a ciência se funda.

Podemos considerar como resultado bastante fecundo do progresso da Psiquiatria no século vigente o advento da orientação psicossomática no campo da Medicina clínica em geral, que, além de enfatizar a noção de unicidade da pessoa humana, veio abrir maiores perspectivas de diagnóstico e terapêuticas na especialidade e em outras em geral.

No campo do tratamento, também no século XX houve notável desenvolvimento na Psiquiatria: 
a partir de 1933 surgem importantes técnicas terapêuticas (convulsoterapia quimica e elétrica, insulinoterapia, psicocirurgia, sonoterapia, entre outras); a introdução dos psicofármacos, por volta da década de 50 representou um extraordinário desenvolvimento para a área, que também se beneficiou dos avanços dos tratamentos psicológicos (psicoterapia) nestes últimos 50 anos. Também a terapêutica ocupacional ganhou espaço, trazendo beneficios para os portadores de doença mental e de toda estrutura assistencial e social dos mesmos.

O conceito de saúde mental, até então, proposto pela medicina havia reduzido a loucura aos limites do campo médico. Gradativamente vai se configurando um movimento de negação de análises especificas, deslocando-se o conjunto das interpretaçōes do modelo médico psicológico para modelos sociológicos, fortemente marcados pela tradiçăo marxista italiana. (Barros, 1994)

A partir da segunda metade do século $X X$, depois dos movimentos de criticas institucionais aos hospitais psiquiátricos nos paises ocidentais, os questionamentos de Goffman (Estados Unidos), da Psiquiatria Social e da Antipsiquiatria (Inglaterra), da Psiquiatria de Setores (França), da Psiquiatria Democrática (Itália) vem se refletindo numa mudança de paradigma da assistência psiquiátrica.

De acordo com Barros (1994), Franco Basaglia, psiquiatra italiano, responsável por uma série de transformações introduzidas na década de 60 , no hospital de Gorizia - Itália, ao ser questionado se aos interesses de natureza social năo corresponderiam outros de natureza técnico-psiquiátrica, foi enfático ao responder que uma delimitação rigida da psiquiatria num campo de saber técnico impediria a compreensão do terreno sociológico, ao qual está interligada, impossibilitando desta forma a superação da internação manicomial.

\section{INICIO DO PENSAMENTO REFORMISTA}

No Brasil a trajetória do atendimento psiquiátrico revela a mesma tendência de outros paises, ou seja de um modelo que exclui e segrega o "louco", passa-se a se preocupar com um atendimento mais humanizado, com vistas a garantir a dignidade do cidadão, portador de doença mental. Embora com algumas dificuldades de assimilar as novas tendências do tratamento psiquiátrico, estamos vivendo um periodo de mudanças ideológicas, estruturais e politicas nas ações de saúde mental, especialmente em relação à institucionalizaçăo da assistência.

Após a década de 70 começa a despontar no cenário nacional questionamentos em congressos, grupos de estudo, frentes de defesa aos direitos humanos ao doente mental, juntamente com o movimento de trabalhadores em Saúde Mental, que iriam protagonizar a crítica do modelo psiquiátrico tradicional, trazendo idéias precursoras do projeto da Reforma Psiquiátrica. Sem dúvida, iniciou-se, assim, um periodo onde o campo das idéias sobrepunhase ao saber e as práticas psiquiátricas.( Nicácio, 1994)

Segundo Amarante (1994), as vindas de Franco Basaglia ao Brasil, no inicio dos anos 80 , contribuiram para que fosse construido aqui um pensamento critico sobre a natureza do saber e das instituições psiquiátricas, a tal ponto que suas posiçőes incorporaram-se em definitivo à trajetória desses movimentos da Reforma Psiquiátrica Brasileira.

Nestes percursos, ele deparou-se com importantes resistências de determinados segmentos: universitário (dominado pela postura psiquiátrica clínica positivista), empresarial da loucura ( que compartilhava dos mesmos paradigmas, além de interesses mercantilistas) e dos psicanalistas (que afirmavam não dar conta da questão dinâmica presente na questão sociológica e de falta de rigor metodológico). Assim, o pensamento basagliano ficou marginalizado no meio acadêmico e nas orientaçőes de politicas em saúde mental.

Por outro lado, houve exceções e as diferentes forças envolvidas no movimento reformista buscavam a construção de um novo modelo assistencial enfatizando os serviços extrahospitalares, visto que o manicômio é compreendido como instituição total onde segrega o 
individuo e o exclui de seu meio social.

A partir de Basaglia, continua Amarante (1994), construiu-se novas formas de assistência psiquiátrica em que o louco, agora cidadão teria direito de receber assistência de fato, diante do seu sofrimento e não mais aquela falsa tutela psiquiátrica, da invalidação e do seqúestro.

Atualmente a prática assistencial no mundo segue as recomendações da Organização Mundial da Saúde, no sentido de se dotar recursos sempre menores aos hospitais psiquiátricos, deslocando-os em direção às estruturas comunitárias mais elásticas e contextualizadas, possibilitando-se intervir de maneira mais individual e humana. (Evaristo, 2000)

Assim, é importante criar novas estruturas e recursos de atenção ao doente mental onde foca-se não mais a doença, mas o doente; não mais as transformaçōes técnicas da assistência (decorrentes do avanço tecnológico, naturalmente valiosas, porém insuficientes), mas as atitudes profissionais adequadas para o enfrentamento da atual realidade.

Campos (1992) enfatiza que um projeto deve ser composto de interesses e necessidades da sociedade, das noções disciplinares, de diretrizes politicas e dos modos de gestão dos sistemas públicos. O autor destaca que o projeto reformista em saúde ainda é muito anti e pouco pró, sendo, no entanto, pelo direito à saúde, pela intervenção do Estado, pela democratização da gestão, entre outros elementos essenciais à construção de uma cidadania efetiva. Para ele, ainda não conseguimos historicamente realizar negação/superação das práticas tradicionais.

Compreendemos que não há como contestar tal pensamento, entretanto, não há também como negar os avanços da psiquiatria, que mesmo de forma diferente, nas várias regiões do Brasil percebe-se um esforço consciente de busca de novas alternativas com vistas a uma nova sociabilidade. O referido autor salienta que os movimentos existentes são insuficientes, na medida em que são mais uma critica do tradicional que uma criação de uma nova cultura psiquiátrica.

É evidente que esta situação, talvez conflituosa e de contrastes é inerente a momentos de transição, faz parte de um processo decorrente do contexto sócio-politico-econômico e cultural, onde o discurso teórico-prático do movimento reformista recebe influência e também influencia o modelo assistencial vigente e aquele a que se propõe.

Amarante (1994) cita o periodo em que Franco Basaglia, ao assumir a direção do manicômio de Gorizia, coordenou os questionamentos sobre as instituiçōes psiquiátricas, ancorado na desconstrução do paradigma psiquiátrico a partir da desmontagem do manicômio, como sintese da instituição a ser negada ${ }^{4}$. Seu pensamento pressupõe um outro olhar para o "louco", liberto da segregação como ủnica resposta institucional, que exige uma transformação nas relações entre individuos e instituições e um redimensionamento na relação saúde-doença. Significa compreender o valor do homem, são ou doente, que vai além do valor da saúde ou da doença.

No entanto, também na Itália, berço da Reforma Psiquiátrica houve impasses na desconstrução de um modelo de assistência cronificante até chegar aos dias atuais, quando ainda se constrói um sistema reconhecido como referência dentro da assistência psiquiátrica no mundo.

Na experiência de Trieste ${ }^{5}$, por exemplo, Barros (1994) diz que os operadores perceberam que mesmo derrubando os muros era necessário acompanhar os pacientes a um social que os exclui, procurando encontrar formas de mediação entre as provaçōes materiais e espirituais e suas possibilidades individuais e existenciais. Continuam, porém a exercer um mandato de

\footnotetext{
4 Coletânea do pensamento basagliano, organizado a partir da experiência de Gorizia, editada na Itália em 1968 que chegou ao Brasil em 1984.

${ }^{5}$ Cidade italiana onde iniciou-se o movimento de desinstitucionalização, na chamada psiquiatria democrática, proposta por Franco Basaglia.
} 
controle social, mesmo no interior de uma instituição transformada. Neste sentido, cita as palavras de Rotelli: "a desconstruçăo prática revelou a perpetuação do mandato de controle da psiquiatria reformada", denotando que o processo exige um profissionalismo capaz de superar os limites da especificidade médico-psicológica, afrontando problemas que se apresentam ainda hoje como demanda de ajuda assistencial. Segundo a autora, desinstitucionalizar a instituição inventada, redimensionar as relações entre a prática politica e social, entre o privado e o público, encerram um grande desafio e um conjunto de dúvidas que ainda abalam a prática triestina atual.

Assim, a trajetória brasileira segue seu percurso na construção de um modelo que atenda aos principios da Reforma Psiquiátrica, "em busca de uma nova psiquiatria, de uma nova cultura de como lidar com a loucura, de como construir um sistema de assistência psiquiátrica que possibilite a reprodução social dos sujeitos, que invente novas referências de sociabilidade, novos espaços de relação, de produção e de humanidade" (Amarante, 1994, p.19). Sem dúvida, espera-se que esta construção venha ao encontro e esteja em consonância com as doutrinas e filosofias da política de saúde, o Sistema Único de Saúde, presentes na Constituição de 1988.

Neste sentido, Campos (1992) chama a atenção para se reforçar os movimentos que procuram redefinir o papel dos profissionais e dos serviços de saúde, para os que recolocam a discussão sobre o significado do cuidado em Saúde Mental e sobre o sentido do processo de cura. $\mathrm{O}$ autor considera que o objetivo de todo trabalho terapêutico é ampliar a capacidade de autonomia do paciente.

De acordo com Nicácio (1994), na prática cotidiana ir ao encontro das necessidades do individuo internado significa desmontar os conjuntos institucionais referidos à doença, romper com o paradigma clinico de redução da loucura em doença mental. Neste percurso desmontase, descontrói-se a resposta cientifica e instituicional (a soluçăo) para desconstruir o problema e recompô-lo, resignificá-lo, complexificá-lo.

Para esta autora o projeto de transformação basagliana não se encerra em uma mudança institucional radical, mas se insere no campo da reflexão epistemiológica do conhecimento, das ideologias, do papel dos técnicos e dos intelectuais.

Barros (1994), por sua vez considera que trata-se de uma reforma institucional, com limites e contradiçōes, que busca construir uma nova ética, no sentido de reorientar as complexas questōes colocadas aos técnicos em saúde pela sociedade moderna. É necessário, pois, desconstruir não só a instituição, mas toda a cultura, as idéias cristalizadas e preconceitos impregnados no imaginário mesmo daqueles que, conscientemente, desejam destruí-lo.

\section{TENDÊNCIAS ATUAIS}

É preciso se pensar num modelo operativo social com outras instituições, além da criação de uma cultura de solidariedade e vivência de cidadania que garanta a inclusão social do individuo, sua autonomia e dignidade.

É um processo que transforma o modo pelo qual as pessoas são tratadas para transformar o seu sofrimento, num conjunto de açőes elementares e complexas com variadas estratégias indiretas e de mediação que tem como projeto a produção de vida, de sentido, de sociabilidade e a utilização de esforços coletivos.

Evaristo (2000) menciona alguns aspectos da assistência psiquiátrica que levam à cronicidade, na medida em que esta não oferece respostas às crises e a seus significados, desconsiderando a interdependência dos problemas psicofisicos-sociais, permitindo que estes e o mal estar se cronifiquem. Destaca a institucionalização, enquanto isolamento, reclusâo, abandono, estigmatização e tratamentos inadequados como elementos propiciadores de um percurso institucional cronificante; assim, sugere que a partir destas reflexőes o primeiro objetivo 
seja o de evitar ou não dar lugar a um percurso patogênico para depois criar um percurso terapêutico.

O autor supra citado considera ainda que a cronificação dos sintomas é sobretudo a cronificação da falta de recursos institucionais e, neste sentido, propõe descronificar a instituição, - que significa modificar regras não mais funcionais, mas de valorização dos sujeitos nas suas funçōes dentro das instituiçōes, suas individualidades e a criatividade dos trabalhadores de saúde. Significa destruir regras manicomiais considerando-se os direitos de liberdade de cada um, que certamente modificará a dinâmica dos hospitais psiquiátricos. Significa, enfim, transformar as relações de poder existentes entre instituição e individuo (não mais paciente), compreendendo-o como membro de um grupo social.

Neste sentido, Leonardis citado por Nicácio (1994) não compreende transformação enquanto execução de objetivos, nem como relação funcional entre intenções e efeitos. Como uma cultura nova, tece uma diferente relação entre cidadãos e instituições, mobilizando como atores todos os sujeitos envolvidos já que a transformação das estruturas das instituiçōes, dos sujeitos e de suas culturas, só pode acontecer simultaneamente. Para este autor, à cultura da inovação é inerente, portanto, uma pluralidade de diferentes linguagens, conhecimentos, concepçöes de mundo. A mudança tem de um lado a auto-transformação dos sujeitos envolvidos, no sentido da disponibilidade a aprender e ao mesmo tempo é produção de realidade com os materiais existentes, em forma intrinsecamente plural e ancoradas na especificidade desses materiais.

É inerente ao processo a multiplicidade de sujeitos que tendem a ser envolvidos como atores/autores; agentes da transformaçăo são os pacientes, os familiares, os profissionais, a comunidade local, as pessoas da rede institucional, os administradores, os sujeitos políticos, enfim, todos os sujeitos sociais, institucionais ou não, que de diferentes formas interagem, atravessam a instituição.

Incorporar estes principios ao tratamento pode significar uma nova visualização de um modelo assistencial diferente que dá espaço a outras modalidades de atendimento, mais voltadas à comunidade, não mais ao "louco" mas às necessidades do cidadão portador de um sofrimento psiquico, num tratamento mais humanizado, mais socializante, mais solidário e mais eficaz.

Estas questōes precisam ser relevadas e discutidas no contexto do qual o individuo faz parte, visando-se suas relações familiares, de trabalho e também assistenciais. Isso evidencia que interagir com o sofrimento da pessoa significa interagir com suas áreas especificas de problemas.

Inserir o individuo no seu meio, dando-lhe a assistência devida, oportuniza-se mais espaços de socialização, de recuperação de suas potencialidades (muitas vezes desprezadas), de reabrir sua comunicação na familia e no seu ambiente social, trazendo a ele possivelmente um sentido mais significativo de existência.

Desse modo, possibilita-se o percurso da reabilitação psicossocial entendendo-o como um processo de reconstruçăo que envolve vários cenários como considera Saraceno (1996): habitat, rede social e trabalho com valor social. Nesta perspectiva, o núcleo familiar tem um papel no processo reabilitativo de cada pessoa assistida, demonstrando que o serviço de saúde amplia o espaço de assistência integral e aumenta a sua resolutividade quando envolve também os familiares na rede de assistência.

Assim, incluir a familia no tratamento significa dar-lhe suporte, além de ampliar a compreensão da dinâmica das suas relações, de forma que se pode nortear a atenção dispensada a este núcleo social.

De acordo com Bassitt (1992) há uma corrente dominante que acredita no papel da familia na determinação do surgimento de doença mental em um de seus membros, tornandoo bode expiatório sobre o qual é jogado todos os problemas.

Macedo citado por Waidman (1999) lembra que por muito tempo os profissionais de 
Saúde Mental tinham a família como produtora de doença mental e não como aliada para recuperar o doente institucionalizado.

Por outro lado, existem outras abordagens para a complexa dinâmica entre familia e o doente mental, deixando de enfatizar esta relação causal determinista no surgimento de um quadro psiquiátrico. É importante salientar que a existência de uma forma patológica de convivio familiar não significa que nela surgirá um doente mental, não se podendo, portanto, fazer um raciocinio único e global que a familia cria seu doente ou este cria distúrbios na família.

Atualmente percebe-se que quando a familia é apoiada e orientada tem condições de compartilhar seus problemas e pode ser percebida com a estrutura existente para a desinstitucionalização e reinserção social do indivíduo.

Há estudos citados por Waidman (1999) que apontam que a familia é fundamental na manutenção do doente fora da instituição psiquiátrica; dai a necessidade dela ser preparada e apoiada pelos profissionais de saúde da área de Saúde Mental com vistas ao seu convivio com o portador de transtorno mental.

Assim, no percurso da assistência em psiquiatria, a consideração da importância da extensão da rede de assistência vem contemplar a pessoa portadora do transtorno mental dentro do contexto de sua existência, convivendo com o sofrimento psiquico advindo da situação.

\section{CONSIDERAÇÕES FINAIS}

As questōes tratadas acima são de relevância para se compreender os rumos da psiquiatria, que passou a dar mais atenção ao paciente e à familia, valorizando suas relações na compreensão e no tratamento do individuo. Neste sentido concordamos com Barros (1994) quando afirma que talvez o momento não seja ainda o de superar a crise, mas de suportá-la de forma a permitir a invençăo de novos saberes, formas de inovação da politica e práticas sociais. " O futuro não está garantido, as formas de racionalidade desafiam a capacidade de inovação das sociedades ocidentais que necessita de uma nova ética, de uma bioética ecológica que possa guiar não apenas o comportamento das pessoas, mas a direção do saber que se quer.... É preciso acolher o desconhecido, entender que desordem não é a não-ordem, que os saberes são sempre inesperados, incertos e nâo definitivos." (p.149)

Estas consideraçőes fazem acreditar que é possivel construir uma nova ética no estabelecimento de relaçōes individuo-sociedade, onde se insere a questão saúde-doença, possibilitando que as relações terapêuticas sejam estabelecidas entre cidadãos. Desta forma, evidencia-se a necessidade de consideração do real valor de cada cenário envolvido, a fim de engajá-los no processo de reconstrução de um novo modelo assistencial.

Faz-se necessário, portanto, construir um projeto terapêutico cujas transformações devem ser discutidas, elaboradas, incorporadas e articuladas com os setores sociais envolvidos no modelo de atenção em saúde a ser proposto.

ABSTRACT:Theoretical-reflective study aimed to comprehend psychiatric assistance by analysing, from a historical perspective, the different conceptions and tendencies which culminated with the Brazilian Psychiatric Reform. The authors question the different trends occurring in health assistance, since the country is facing a period of ideological, structural and political transformations in terms of Mental Health actions, which point to possible changes in the present psychiatric care model.

KEYWORDS: psychiatric assistance, psychiatry, mental health

RESUMEN: Buscamos mediante una revisión bibliográfica critica comprender las distintas concepciones teóricas y las tendencias de actuación que culminaron con la Reforma Psiquiátrica Brasileña. Nuestra critica se traduce en los planteamientos de los rumbos de la asistencia, una vez 
que actualmente estamos en un momento de transformaciones ideológicas, estructurales y politicas en las acciones de Salud Mental, que fundamentarian un posible cambio en el modelo vigente.

PALABRAS CLAVE: asistencia psiquiátrica, psiquiatria, salud mental

\section{REFERÊNCIAS BIBLIOGRÁFICAS}

AMARANTE, P. A tradição basagliana de uma nova psiquiatria. In: BARROS, D.D., Jardins de Abel: desconstrução do manicômio de Trieste. São Paulo: EDUSP, 1994. p.17-20.

BARROS,D.D. Jardins de Abel: desconstrução do manicômio de Trieste. Săo Paulo: EDUSP, 1994. $155 \mathrm{p}$.

BASSITT, W. O conceito de familia. In: D'INÁCIO, M. (Org.) Doença mental e sociedade: uma discussão interdisciplinar. Rio de janeiro: Qrad, 1992. p.278-287.

CAMPOS, G.W.S. Modelos de atençāo em saúde pública: um modo mutante de fazer saúde. Saúde em debate, n. 37, p.16-19, 1992.

EVARISTO, P. Gestäo da psiquiatria na comunidade. Traduçăo de Maria Alice Pereira. UNOPAR CIENT. CBS, Londrina, v. 2, n. 1, p.27-34, out. 2000.

NICÁCIO, M.F. O processo de transformação da Saúde Mental em Santos: desconstrução de saberes, instituiçōes e cultura. 1994. Dissertação (Mestrado) - Pontificia Universidade Católica de São Paulo, Sāo Paulo.

ROTELLI,F. Le Nuove Intituzione della Psichiatria. Trieste: Centro Studio F. V., 1979. Mimeogr.

SARACENO, B. Reabilitação Psicossocial: uma estratégia para a passagem do milênio. In: PITTA, A. (Org.) Reabilitação Psicossocial no Brasil. São Paulo: Hucitec, 1996. p 13-18.

SOLOMON, P.; PATCH, V.D. Manual de Psiquiatria. São Paulo: Atheneu,1975. 713p.

WAIDMAN, M.A.P. Enfermeira e familia compartilhando o processo de reinserção social do doente mental. In: LABATE, R.C.(Org.) Caminhando para a assistência integral. Ribeirão Preto: FAPESP, 1999. p. 389-407.

Recebido em agosto de 2000

Aprovado em março de 2001 